\title{
CRÍTICA MUSICAL Y PENSAMIENTO ESTÉTICO EN LA ESPAÑA DE LA RESTAURACIÓN: JOSÉ Ma ESPERANZA Y SOLA (1834-1905)
}

\author{
MUSIC CRITICISM AND AESTHETIC THOUGHT IN THE SPANISH \\ RESTORATION: JOSÉ M $M^{a}$ ESPERANZA Y SOLA (1834-1905)
}

\author{
Manuel Sancho García \\ Universitat de València
}

\begin{abstract}
Resumen
La crítica musical en la España de la Restauración tiene en José María Esperanza y Sola (1834-1905) una de sus plumas más representativas, activo durante treinta años, desde finales de la década de 1860 hasta las postrimerías del siglo. En el transcurso de esta etapa, Esperanza colaboraría en distintas publicaciones periódicas y, singularmente, la revista "La Ilustración Española y Americana", desde cuyas páginas se asomará a la realidad musical española, dando cuenta de los sucesos musicales de mayor relevancia verificados en Madrid, juzgados según un ideario estético de corte netamente conservador, opuesto a toda novedad que contraviniese el sistema musical vigente. Sobre la base del pensamiento del crítico madrileño, nuestro estudio propone un recorrido a través de los diferentes bloques temáticos que integran su producción periodística.
\end{abstract}

\section{Palabras clave}

Restauración española, crítica musical, siglo XIX, "La Ilustración Española y Americana”, Esperanza y Sola, Peña y Goñi, ópera italiana, Wagner.

\section{Esperanza y Sola en la crítica musical española de su tiempo}

Dominando el panorama de la crítica musical en España durante el último tercio del siglo XIX, descuellan dos personalidades de la talla intelectual de Antonio Peña y Goñi y José María Esperanza y Sola, autores ambos de una fecunda obra musicográfica publicada en diversos medios de comunicación a lo largo de tres décadas, desde finales de los años sesenta hasta las postrimerías de la centuria. A falta de

\begin{abstract}
One of the most outstanding figures of music criticism in the Spanish Restoration was José María Esperanza y Sola (18341905 ), active for thirty years, from the late 1860s until the end of the century. During this period, Esperanza collaborated in different periodical publications and, particularly, "La Ilustración Española y Americana", from whose pages he informed about the most important musical events celebrated in Madrid, judged according to a conservative aesthetic criterion, opposed to any novelty that infringe the traditional music system. On the basis of Esperanza's thought, our study analyzes the different subjects that constitute his journalistic production.
\end{abstract}

\section{Keywords}

Spanish Restoration, music criticism, 19th century, "La Ilustración Española y Americana”, Esperanza y Sola, Peña y Goñi, Italian opera, Wagner. una catalogación completa de la producción de Peña, que fácilmente podría alcanzar los trescientos títulos, el donostiarra ha sido objeto de distintas aproximaciones en virtud de las cuales conocemos su perfil individual como crítico, junto con las orientaciones e intereses estéticos que le guiaban ${ }^{1}$.

1 Consúltense, a este respecto, CASARES (1995): 481-484. GRACIA IBERNI (1994): 201-213. GRACIA IBERNI, 4 (Madrid, 1997): 3-13. GRACIA IBERNI (2001), vol. 8: 581-583. 
Frente a éste, el madrileño Esperanza y Sola, fuera de alguna aportación puntual ${ }^{2}$, se muestra a fecha de hoy carente de un estudio con que dibujar los rasgos definitorios de su creación periodística, alrededor de ciento sesenta artículos, recogidos a título póstumo en tres volúmenes bajo el epígrafe de Treinta años de crítica musical ${ }^{3}$. Esperanza desarrolló especialmente sus tareas como cronista en la revista La Ilustración Española y Americana ${ }^{4}$, desde cuya tribuna se erigirá en testigo privilegiado del devenir de la música en la España de la Restauración, suministrando pormenorizada información sobre los acontecimientos musicales más significativos de la capital madrileña. No por ello renunciaría a emitir su valoración y juicio personales, asumiendo así el papel de intelectual comprometido, fiel a sus principios y convicciones, que defendió con firmeza, alejado no obstante de la vehemencia de la pluma de Peña y Goñi. Felipe Pedrell, a últimos de siglo, calificaba a Esperanza como "crítico musical de seguro e imparcial juicio, puede decirse de su vasta producción literaria que es la historia verídica del movimiento musical contemporáneo español" ${ }^{5}$. En efecto, confluyen en las crónicas de Esperanza cuestiones tan candentes y aun polémicas en su día como la recepción de la estética wagneriana, enfrentando en dos bandos irreconciliables a partidarios y detractores del compositor germano; la creación de una ópera nacional, aspiración traducida en diversas iniciativas infructuosas y $\sin$

2 CASARES (1995): 480-481. CASARES (1999), vol. 4: 768769. Una reseña muy breve, en MOYA, 12 (Albacete, 1997): 170. En fechas recientes, Sonia Gonzalo ha ofrecido las conclusiones de un primer acercamiento más serio y riguroso [GONZALO (2013): 1677 1698].

3 ESPERANZA (1906), 3 vols. Al cotejar las fechas consignadas de publicación de cada artículo con los correspondientes números originales, hemos detectado algunos errores, achacables a José Ramón Mélida, responsable de la edición, o acaso al propio Esperanza, quien coleccionó todos sus escritos de crítica musical, añadiendo un índice cronológico para facilitar su ordenación. Obviamente, en aras del rigor histórico, nos regiremos por los documentos hemerográficos, sin perjuicio no obstante de apuntar en su caso las discrepancias halladas respecto al libro sobre Esperanza.

4 Hablamos, con certeza, de una de las publicaciones periódicas más destacadas de la España del último tercio del siglo XIX y comienzos del XX. Continuación de El Museo Universal, fue fundada en 1869 por Abelardo de Carlos y viviría una dilatada existencia, que llega hasta 1921. Se anunciaba como "periódico de ciencias, artes, literatura, industria y conocimientos útiles". Incluye grabados, noticias de actualidad, artículos de divulgación sobre historia, literatura, artes, avances científicos y tecnológicos, expediciones intercontinentales, etc., relatos, poesías, crítica literaria y teatral, pasatiempos y curiosidades. La revista se caracterizó por la calidad de sus ilustraciones, que recreaban diferentes aspectos de la vida cotidiana española e hispanoamericana. Algunos de sus colaboradores más insignes fueron José Zorrilla, Ramón de Campoamor, Juan Valera, Leopoldo Alas Clarín, Emilio Castelar, Valle-Inclán y Unamuno. Vid. B. MÁRQUEZ, 13-14 (Sevilla, 2005): 185-209.

5 PEDRELL (1897): 558. repercusión ulterior; las vicisitudes de la zarzuela grande, en franca decadencia, y un género chico más popular, no siempre aceptado de buen grado por la crítica española; o la lenta pero paulatina aclimatación de la música instrumental culta de la mano de la Sociedad de Cuartetos y la Sociedad de Conciertos de Madrid.

\section{Perfil biográfico}

El arqueólogo y escritor José Ramón Mélida, quien se contara entre los amigos más íntimos de Esperanza y Sola, traza su retrato biográfico en el prólogo del primer tomo de Treinta años de crítica musical, donde relata los sucesos esenciales de la trayectoria vital y profesional del crítico madrileño, con profusión de detalles acerca de su personalidad, carácter y cualidades morales. Nacido en 1834, proveniente de una familia acomodada ${ }^{6}$, Esperanza cursa estudios en la Universidad Central, obteniendo en 1857, a los veintitrés años de edad, la licenciatura de Jurisprudencia y, poco después, la de Administración y el doctorado en Derecho ${ }^{7}$. Sus excelentes aptitudes para el arte musical le animarán a recibir lecciones de Hilarión Eslava, teniendo por condiscípulo a Jesús de Monasterio. Pianista notable, sin mayores ambiciones que su propia satisfacción personal, participa Esperanza en numerosas veladas filarmónicas de la capital de España, donde se rendía culto a la música "clásica". Probó asimismo sus armas como compositor, en el estilo pianístico de salón característico de la época, alumbrando algunas páginas menores, de correcta factura, entre valses, polcas y pasodobles. De resultas de tales aficiones, Esperanza pronto comienza a reunir libros de historia y crítica musical que, junto con títulos de otras disciplinas, habrían de conformar su nutrida biblioteca, provista de más de setecientos volúmenes ${ }^{8}$. Simultáneamente, instado por varios amigos, emprende la actividad de crítico musical, "especialidad para la que reveló desde luego poseer excepcionales condiciones, por su rectitud de juicio, su delicado

6 Su padre, Juan Martín Esperanza, natural de Alcalá de Henares, ocupaba el puesto de Agente Fiscal del Real y Supremo Consejo de Castilla. Por su parte, el abuelo materno, Diego Sola Oxer, era Secretario del Consejo de S. M., Intendente honorario de Provincia y Jefe de Sección de la Dirección General de Rentas.

7 El discurso leído por Esperanza en el acto académico de investidura versó sobre las relaciones entre el Cristianismo y el Derecho. Vid. ESPERANZA (1858).

8 A su muerte, acaecida en 1905, los testamentarios del crítico hicieron entrega de estos volúmenes a la Real Academia de Bellas Artes de San Fernando, donando al Conservatorio sus "papeles de música", en número de seiscientos, que agrupaban partituras de música religiosa, óperas y piezas de concierto. Vid. Revista de archivos, bibliotecas y museos, IX/11-12 (1905). 
modo de sentir, sus conocimientos técnicos y su cultura". El primer artículo saldrá a la luz el 23.03.1868, publicado en la Revista y Gaceta Musical, bajo el seudónimo de "F. de S. Iriarte". Siguen sucesivos trabajos en La Ilustración de Madrid, Gaceta del Sport, Revista Europea, La España Católica, Almanaque de la Ilustración, El Cronista, La Crónica de la Música, La Integridad de la Patria y, singularmente, La Ilustración Española y Americana donde, a partir de 1879 , colaboraría con asiduidad por espacio de veinte años, al frente de la sección "Revista musical", hasta su postrera crónica, fechada en enero de $1899{ }^{10}$. Como consecuencia de los méritos que contrajo durante este tiempo, Esperanza fue nombrado en 1888 miembro de la Real Academia de Bellas Artes de San Fernando, en calidad de crítico musical, sustituyendo a Rafael Hernando ${ }^{11}$.

Pese a la fama y reputación de que gozara en su faceta musicográfica, la ocupación profesional principal de Esperanza se desplegó en la Administración pública, en cuyo seno desempeñó diversos cargos de elevada responsabilidad: Oficial de la Secretaría de la Presidencia del Consejo de Ministros, Oficial de la clase de mayores del Consejo de Estado y, desde 1896, Secretario general de dicho cuerpo. Concurrente habitual a los salones de la distinguida sociedad matritense, Esperanza se granjeó la amistad de aristócratas, políticos, intelectuales y artistas, entre los que figuraban algunos de los representantes más ilustres de la vida musical local, como Baltasar Saldoni, Jesús de Monasterio, Francisco Asenjo Barbieri, Mariano Vázquez y, particularmente, Santiago de Masarnau, con quien mantuvo una estrecha relación casi fraternal. Gracias a éste, nuestro crítico ingresaría en la Sociedad de San Vicente de Paúl, una institución benéfica consagrada a la caridad y las obras piadosas ${ }^{12}$. Cristiano devoto, poseedor de profundas y acendradas creencias espirituales, Esperanza invirtió todos los esfuerzos durante medio siglo, sin contar gran parte de su capital, en el sostenimiento de la citada entidad, donde llegará a ocupar la vicepresidencia. Mélida.

9 ESPERANZA (1906), vol. I: 14. Comentario de José Ramón

10 Hasta 1874, Esperanza ocultó su identidad bajo la inicial "H" o el apodo "Hoffnung". Desde esta fecha, adopta ya su verdadero nombre.

11 Consúltese SUBIRÁ (1980): 128-129, 131 y 232. Elegido el 26.12.1888, Esperanza tomó posesión del cargo el 31.05.1891, con un discurso sobre la crítica musical del P. Esteban de Arteaga.

12 Creada en París en 1833, Masarnau la implantó en España, constituyéndose oficialmente en 1850. Vid. SUÁREZ (1994).

\section{Rasgos estilísticos}

Jesús de Monasterio señalaba con nitidez las características de la crítica de Esperanza:

Su crítica, a decir verdad, además de distinguirse por su buen gusto estético y por la amenidad del estilo, es desapasionada, y sin faltar a la justicia, es más benévola que severa; no es acerba ni sistemática, ni en ella se hace alarde de pedantesca sabiduría, por más que dé ostensibles pruebas de su ilustración; no es menos ingeniosa que discreta, ni escasea el chiste, siempre decoroso, y aunque algunas veces muéstrase satírica, nunca se la ve acercarse a los linderos de la chocarrería o de la inconveniencia. En fin, los escritos del Sr. Esperanza honran a su autor sin deshonrar jamás a los que son a veces el blanco de sus censuras ${ }^{13}$.

Una clasificación de la obra de Esperanza abarcaría cinco grandes ejes temáticos: crónicas teatrales, que cubren funciones operísticas y de zarzuela, verificadas por lo común en el Teatro Real; reseñas de sesiones de la Sociedad de Cuartetos y la Sociedad de Conciertos; biografías y estudios sobre músicos, así compositores como intérpretes, a veces con ocasión de su reciente fallecimiento; recensiones de libros; a lo que debemos agregar un último apartado, englobando asuntos varios sin conexión con los precedentes, como artículos a propósito de la decadencia de la música sagrada en España, recitales de instrumentistas, ejecución de piezas sacras en celebraciones religiosas, etc. Las críticas de Esperanza aparecieron esporádicamente, sin guardar ninguna periodicidad en el tiempo. Liberado, por tanto, de la crónica cotidiana, Esperanza fijará la mirada en aquellos sucesos musicales de mayor relieve acontecidos en Madrid o que, a su entender, ofrecían algún elemento de interés.

Existe, claramente, una línea de continuidad entre el estilo de los primeros textos de Esperanza correspondientes a la década de 1870 y sus últimas aportaciones al cerrarse el siglo. Cabe hablar, a grandes rasgos, de crónicas extensas -a menudo, en exceso- y razonadas, fruto de la serena reflexión, donde se aúnan, por un lado, la amenidad y el tono didáctico y, por otro, la erudición, sin perjuicio de acudir, cuando asî conviene a sus propósitos, al fino humor, la sutil ironía o la anécdota graciosa. Esperanza adorna su discurso con toda suerte de citas y comentarios de diferentes autores, ya del ámbito específicamente musical -compositores, intérpretes,

13 Discursos leídos ante la Real Academia de Bellas Artes en la recepción pública del Excmo. Señor D. José M. Esperanza y Sola, el día 31.05.1891. Madrid, 1891: 74-75. 
tratadistas, musicólogos-, ya de cualquier otra área o rama del conocimiento, demostración palpable de la sólida cultura y preparación intelectual que atesoraba el musicógrafo. Este procedimiento obedecía a tres motivos: ilustrar sus argumentaciones a guisa de apoyo, arrojar luz sobre cierta cuestión o refutar opiniones ajenas, corroborando las propias. Sin afán de exhaustividad, un listado semejante contendría a Platón, San Agustín, Goethe, Schumann, Fétis, Cervantes, Berlioz, el padre Feijoo, Molière, Eximeno, Santa Teresa, Baudelaire, Liszt o Stendhal, entre la infinidad de nombres que pueden enumerarse.

Esperanza define su crítica como impresionista, esto es, inspirada por el cúmulo de ideas, emociones y sensaciones que suscita determinado hecho musical ${ }^{14}$, "dado que no me creo con el saber y autoridad suficientes para ejercer la verdadera crítica, de tal modo que, puedo asegurarle, mi ánimo al acudir donde se oye buena música, es aprender y ponerme $[\ldots]$ en camino de llegar algún día a la realidad" ${ }^{15}$. Defiende, ante todo, la narración objetiva e imparcial, al margen de cualquier apasionamiento o exclusivismo, que "no son los elementos más a propósito para formar un acertado juicio" ${ }^{16}$. Apelando al recurso del consejo, las valoraciones de Esperanza se muestran, en general, benevolentes, inclinadas a la indulgencia y la comprensión. Ello no obsta para que, si así lo estimase oportuno, aplique sin complejos el juicio severo ante cualquier aspecto o circunstancia recriminables. Las censuras más aceradas se dirigen, de una parte, a la ausencia de novedades en la cartelera teatral, con la consiguiente reposición de los mismos títulos y, de otra, a la mediocridad de numerosos montajes del Real, producto de la improvisación, que se reflejaba, invariablemente, en la desacertada elección del elenco de artistas, la escasez de ensayos, la falta de efectivos orquestales, las licencias respecto al vestuario o la pobreza e inadecuación histórica de los decorados. Menudean asimismo las diatribas destinadas a los cantantes de la "orden del grito", es decir, partidarios del volumen sonoro frente a la tradición belcantista, y a quie-

14 El musicólogo Eustoquio de Uriarte, coetáneo de Esperanza, exigía ennoblecer la crítica española de su tiempo, liberándola de este carácter subjetivo, "sometido a los gustos del vulgo", y abogaba por su profesionalización sobre la base de la "sana y racional estética" [URIARTE (1904): 61-65]. La búsqueda de la valoración crítica objetiva con aspiraciones de universalidad alcanza nuestros días. Según Leopoldo Hurtado, la finalidad estriba en otorgar al juicio equívoco y fluctuante cierta estabilidad y poder de convicción, así como enunciarlo de modo que refleje las cualidades objetivas del hecho analizado [HURTADO (1988): 38-39].

15 La Ilustración Española y Americana (en adelante IEA), XXIV/16 (30.04.1880) [ESPERANZA (1906), vol. I: 268].

16 IEA, XXX/9 (08.03.1886) [ESPERANZA (1906), vol. II: 157]. La fecha no es 8 de mayo, como se indica en el libro. nes cantaban "sin compás" o agregaban a placer variaciones $\mathrm{y}$ añadidos en sus respectivos papeles, ignorando las indicaciones de la partitura. Así las cosas, Esperanza no habría de escatimar oportunidades para reclamar un mayor grado de rigor y exigencia en la puesta en escena de las obras, "ya buscando la posible igualdad en el valer de los artistas a quienes se encomendasen; ya ensayándolas con esmero y cuidado repetidas veces, y no haciendo tan sólo rápidas y poco atentas lecturas" ${ }^{17}$. A ello debía sumarse la presentación regular de nuevos y variados repertorios, capaces de satisfacer a un público hastiado de las mismas y monótonas producciones. Resultaba, además, del todo innecesario contratar a figuras extranjeras de renombre internacional que percibían sumas desorbitantes por cantar cada noche apenas tres o cuatro piezas,

...sino formando cuadros de compañía de artistas aceptables que cumplan bien, procurando una igual interpretación de las obras musicales, y haciendo que éstas se pongan en escena, no de la manera mezquina y, por lo común, extraña a toda verdad histórica, que es tradicional en nuestro coliseo, sino cual cumple a un teatro de primer orden, como es el Real ${ }^{18}$.

\section{Ideario estético}

Diversas opiniones han puesto de relieve los intereses artísticos que rigen los trabajos de Esperanza y Sola. Entre los coetáneos del madrileño, el escritor y periodista José Fernández Bremón apuntaba que sus preferencias musicales "no estaban muy de acuerdo con las ideas dominantes" ${ }^{19}$. Más explícito se muestra José Borrell, para quien las crónicas de Esperanza, en consonancia con la crítica musical madrileña de esa época, pecan de excesivo conservadurismo, y "aunque de un espíritu muy retrógrado, abarcaron todos los géneros musicales, desde la ópera a la música de cámara, cosa que no hacían sus congéneres, los que se limitaban al género teatral" ${ }^{20}$. Ciertamente, sin oponer un rechazo frontal a toda novedad foránea -léase wagnerismo-, no es aventurado afirmar que los gustos estéticos de Esperanza se inscriben en la tradición de la primera escuela vienesa respecto al género instrumental y a caballo entre la ópera romántica italiana encabezada por Rossini, Bellini y Donizetti y la gran ópera meyerbeeriana. Lo aclaraba el propio crítico:

17 IEA, XXX/13 (08.04.1886) [ESPERANZA (1906), vol. II: 183].

18 IEA, XLI/2 (15.01.1897) [ESPERANZA (1906), vol. III: 325].

19 IEA, XLIX/40 (30.10.1905)

20 BORRELL (1945): 219-220. 
Mis tendencias, mis afecciones y mis estudios habrían de llevarme allí donde Mozart es una gloria del arte, la música de Haydn deleita, Beethoven es astro sin rival, y son tenidos como colosos en el género lírico-dramático Rossini y Meyerbeer ${ }^{21}$.

La música, explica Esperanza, constituye el lenguaje artístico que más directa y hondamente impresiona el alma y conmueve al corazón. De ahí se deduce que aspire tanto a agradar como excitar las pasiones y mover los afectos, ya infundiendo sentimientos de alegría o tristeza en el oyente. Sobre la base de la inspiración, Esperanza apuesta por el dominio de la melodía, clara y expresiva, bien se revista de formas sencillas, como Bellini, bien ataviada con todas las galas de la armonía y el contrapunto, según hiciera Meyerbeer ${ }^{22}$. El ideal musical radicaría, por consiguiente, en el maridaje entre una línea melódica inspirada y las riquezas del acompañamiento armónico, "no encubriendo y ahogando a aquélla, antes bien realzándola y aumentando su belleza y encanto" ${ }^{23}$. Una pieza, a fin de conmover, no requiere grandes medios. Es, en este punto, donde Esperanza arremete contra Wagner achacándole la responsabilidad de haber extraviado el rumbo de la música contemporánea. Movidos sus adeptos por el afán de originalidad a todo trance y ocultando, las más de las veces, la carencia de genio y vena inventiva, desdeñaron las reglas de composición convencionales para perseguir los efectos rebuscados y extravagantes, las complejidades armónicas y el abuso de la instrumentación, en detrimento de la transparencia melódica ${ }^{24}$.

En lo tocante al ámbito de la interpretación musical, Esperanza, convertido en salvaguarda de la tradición, someterá a examen el cometido de los cantantes conforme al modelo canoro impuesto por el estilo belcantista, que tendía a privilegiar el canto legato y expresivo, la pureza de emisión, la dicción clara y precisa y el virtuosismo vocal. En reiteradas ocasiones, Esperanza hubo de lamentar la pérdida progresiva del arte del belcanto en favor del "grito a pulmón", el canto estridente y exagerado, que instaurara Verdi en sus primeras óperas ${ }^{25}$. Entre los artistas, ya en franca minoría, adscritos a dicha escuela lírica, Adelina Patti encarnaba ple-

21 IEA, XXV/12 (30.03.1881) [ESPERANZA (1906), vol. I: $317]$.

22 La España Católica (24.12.1874) [ESPERANZA (1906), vol. I: 90].

23 IEA, XXIV/40 (30.10.1880) [ESPERANZA (1906), vol. I: 285].

24 IEA, XXXIX/1 (08.01.1895) [ESPERANZA (1906), vol. III: $250]$. vol. I: 25]. namente esa concepción de canto bello, sentido y emotivo con que Rossini o Bellini conquistaron el orbe operístico:

Su voz de soprano, de extensión excepcional, de timbre argentino y puro [...], de sin igual frescura, suave, dulcísima al par que brillante [...]; es la artista que siente lo que dice; que subraya las frases con verdadera pasión y sentimiento, y que como actriz tiene momentos verdaderamente inspirados ${ }^{26}$.

La misma exigencia de ejecución nítida y calidez expresiva puede trasladarse a la música concebida para instrumentos. Esperanza constata la tendencia general de sacrificar la expresión y el sentimiento por la técnica, según éste un mero auxiliar de aquellas cualidades que, en íntimo y estrecho vínculo, conferían al músico la condición de verdadero artista: "Entre el pianista que ejecuta con una precisión y claridad irreprochables [...], y otro que, menos cuidadoso, en un momento dado, revele, en su manera de decir, corazón y alma, no vacilo: dejo al primero que haga las delicias de los apasionados de la gimnasia del piano, y acepto el segundo" ${ }^{27}$. Todo intérprete, sin distinción de nombre o categoría, es evaluado de acuerdo con estos criterios, desde los pianistas Rubinstein, Sauer, Saint-Saëns o Planté, hasta virtuosos del violín, como Sarasate o Monasterio. Un ejemplo ilustra nuestra afirmación: Sarasate, al decir de Esperanza, exhibía un dominio absoluto sobre el violín: técnica perfecta, exquisita afinación y elegancia incomparable, elementos que le permitían vencer cualquier escollo de la partitura. Por el contrario, su música no traslucía ningún rasgo de pasión y sentimiento o, en otras palabras, "ese soplo del genio, que ni el talento da ni por el estudio se alcanza, con el cual se conmueven las más ocultas fibras del corazón" ${ }^{28}$.

\section{Temas de crítica musical}

\section{Wagner y la escuela wagneriana}

Desde los inicios de su carrera periodística, Esperanza manifestó una inequívoca postura ambivalente hacia la música de Wagner y las consecuencias de su reforma operística ${ }^{29}$. Pesaban, es obvio, sus intereses estéticos, firmemen-

26 IEA, XXIV/46 (15.12.1880) [ESPERANZA (1906), vol. I: 295-296].

27 IEA, XXVI/48 (30.12.1882) [ESPERANZA (1906), vol. I: 438]. La fecha no es 20 de diciembre, como consta en el libro.

28 IEA, XXV/18 (15.05.1881) [ESPERANZA (1906), vol. I: $333]$.

29 Para el estudio del proceso de recepción de Wagner en el Madrid del XIX, remitimos a SUÁREZ (2002), donde se recogen algunos artículos de Esperanza. 
te asentados ya en los primeros artículos, que le inducían a rechazar de plano los presupuestos teóricos del compositor germano en razón de su radical ruptura con la tradición operística italiana. Con todo, no parecía tarea fácil sustraerse al influjo de Wagner, cuyas incuestionables aportaciones en el género lírico-dramático habían trazado la senda de la Europa musical del momento ${ }^{30}$. A juicio de Esperanza, la revolución wagneriana implicaba el retorno al concepto originario de drama musical propuesto por Gluck, en aras de una mayor adecuación a los fines de la expresión dramática. Entre sus resultados más visibles, la música operística había abandonado la estructuración formal uniforme y rutinaria -en alusión a los distintos números cerrados- a que se acomodaban hasta entonces todas las composiciones, sea cual fuere la situación dramática concreta ${ }^{31}$.

Contempladas globalmente, las óperas de Wagner eran obra de un genio, si bien desigual, contradictorio. Del alemán ensalza su inteligencia musical privilegiada, la fecunda inspiración y el dominio de que hacía gala en la ciencia armónica y la orquestación. El gran error estribaba en forzar sus teorías para recrearse en procedimientos extraños e inusuales, que rayaban la excentricidad ${ }^{32}$. En efecto, al renunciar deliberadamente a la melodía y los principios compositivos básicos, la música de Wagner deviene en ampulosa y complicada, resultando abstrusa para la generalidad de oyentes:

(Wagner) ha sido un mal, en cuanto, aferrado a sus más extremadas doctrinas, ha lanzado el arte en un camino de nebulosidades y de vaguedad, llenando sus óperas de eternos recitados, de trozos de música de desmesuradas dimensiones, ligados entre sí [...] por un hilo melódico imposible de $\operatorname{coger}{ }^{33}$.

Wagner demostraba su talento cuando lograba entregarse a la espontaneidad de su numen. Así, en ciertos pasa-

30 Un repaso a los postulados estéticos del escritor y crítico musical Luis Carmena y Millán $(* 1845 ; \nmid 1904)$ confirma la afinidad de intereses artísticos que le unía con Esperanza. Reproduciendo casi literalmente sus argumentos, Carmena comparte la admiración hacia Wagner, pero desaprobaba su encumbramiento por cuanto el alemán, abominando de la tradición italiana, había arrastrado el arte musical a un futuro incierto y oscuro. En tal sentido, Carmena añoraba una pretendida edad dorada en la música europea que, remontándose a Mozart, había desembocado en Rossini, Meyerbeer, Bellini y Donizetti [CARMENA (2004): 354-357]. 479-480].

31 IEA, XXVII/7 (22.02.1883) [ESPERANZA (1906), vol. I:

32 Este cambio de rumbo da comienzo, según Esperanza, a partir de Tristán, y se acentúa en la Tetralogía y, en menor grado, Parsifal. 480]. jes, como la "Marcha" de Tannhäuser o el "Coro nupcial", perteneciente a Lohengrin, donde el maestro de Leipzig emplea modelos compositivos clásicos, Esperanza se deshace en halagos hacia la belleza que encerraba su música, insuperable y sin parangón. Otra página, la "Cabalgata de las Walkirias", acaba convirtiéndose, empero, en un pandemónium, un aquelarre instrumental "que nada habla al corazón, que ningún sentimiento despierta, y que todo el efecto que produce es sacar de tino los nervios del más linfático de los oyentes" ${ }^{34}$. A la luz de semejantes aseveraciones, no debe, por tanto, sorprender que Esperanza negara a Wagner su pretendida condición de apóstol de la nueva era, el Lutero de la "música del porvenir", pese a admitir sin reservas sus contribuciones fundamentales en el campo del teatro musical.

El movimiento wagneriano, pensaba Esperanza, desencadenó la crisis que sufría la música de Europa. En breve tiempo, el wagnerismo había traspasado las fronteras alemanas para adueñarse de Francia e Italia, seduciendo a compositores como Massenet, Verdi, Boito o Puccini, los cuales renegaron del pasado artístico de sus respectivas naciones a fin de abrazar el credo wagneriano. En los trabajos operísticos de estos autores se evidenciaba el "espíritu de agitación" de la moderna música europea, plasmado en la ausencia de líneas melódicas de perfiles definidos, que cedían su protagonismo a melopeas ambiguas e inconclusas, el quebrantamiento intencionado de las leyes armónicas, la modulación casi constante o el predominio de la orquesta, a la que se confiaba el desarrollo de la acción dramática, relegando el canto a una función subalterna ${ }^{35}$. Cualquier excusa es idónea para anatematizar a la facción wagnerista. A propósito de la audición de La Sonnambula, declaraba Esperanza:

Saturado de música wagneriana, y harto de la de sus imitadores, más o menos desdichados, en el drama lírico, siento indecible placer al oír obras cual la Sonámbula [...], al escuchar sus melodías, no sólo se reconcilia uno con el pasado, sino que, con uno de los más grandes maestros en el arte del presente siglo, desea su retorno, como remedio a tanto rebuscamiento, tanto alarde de armonía y contrapunto, y tanto olvido de las más triviales reglas... ${ }^{36}$.

34 IEA, XXIX/16 (30.04.1885) [ESPERANZA (1906), vol. II: 84]. La fecha no es 30 de agosto, como indica el libro. 35 IEA, XXXI/11 (22.03.1887) [ESPERANZA (1906), vol. II: 260]. 250]. 


\section{La escuela italiana: del belcantismo rossiniano al verismo de fin de siglo}

Paladín del melodismo italiano, Esperanza reflexiona acerca de los derroteros que la música de aquella nación venía tomando, luego de los años dorados de Rossini, Bellini y Donizetti. Al reinado de la melodía, en obras cuyo objetivo era conmover deleitando, siguió una fase de perniciosa influencia wagneriana, con efectos nefastos para la creación musical italiana ${ }^{37}$. En tales circunstancias, no acertaba Esperanza a entender esa incondicional sumisión a un ideario extranjero a cambio de traicionar la gloriosa herencia con que el país transalpino había monopolizado la escena operística desde el siglo XVII: “¿Cómo el divino arte de los italianos se ha cambiado en un caprichoso montón de notas ensordecedoras y salvajes? ¿Cómo ha dominado el fragor de los instrumentos a la melodía de la voz humana, lo extraño, lo rebuscado y lo difícil, a lo sencillo, espontáneo de antes?" ${ }^{38}$. Como cabe suponer, Esperanza se decanta por el primer estilo, esto es, el atractivo melódico de cualquier ópera de Rossini frente al cansancio y aturdimiento que generaban en su ánimo, verbigracia, los recientes estrenos de Verdi.

Entre la extensa nómina de compositores nacidos en Italia, Gioacchino Rossini constituye, con mucho, el autor predilecto de Esperanza, a quien no vacila en calificar como "el genio más grande del arte músico en nuestro siglo" ${ }^{39}$. Dos de sus óperas destacaban sobre las demás, El barbero de Sevilla, una pieza maestra de eterna juventud, sin igual frescura e inspiración admirable ${ }^{40} \mathrm{y}$, fundamentalmente, Guillermo Tell, que contenía, ya en estado germinal, ya plenamente desarrollados, cuantos avances se habían atribuido a la escuela wagneriana -en particular, la técnica del leitmotiv-, así como "todos los acentos posibles de la pasión y del afecto, todas las situaciones dramáticas, los modelos más acabados del canto y de la instrumentación, y en la que todas sus páginas eran una norma y un consejo" ${ }^{41}$. Pese a que Bellini no llegó en el curso de su breve biografía a dominar todos los secretos de la ciencia musical, su estilo se distinguía por la imaginación poética, la expresión de los afectos del corazón y la sencillez de unas melodías de innegable belleza,

37 IEA, XXX/1 (08.01.1886) [ESPERANZA (1906), vol. II: 130-132].

38 IEA, XXXIX/1 (08.01.1895) [ESPERANZA (1906), vol. III: 250-251].

39 IEA, XXX/13 (08.04.1886) [ESPERANZA (1906), vol. II: $176]$. $132]$.

40 IEA, XXX/1 (08.01.1886) [ESPERANZA (1906), vol. II: $176]$. aspectos que aparecían sintetizados en I puritani, con certeza su producción de mayor interés ${ }^{42}$. Equiparable a aquél, Donizetti es reputado como uno de los maestros más insignes del arte músico en el siglo XIX. De su catálogo, Esperanza aplaude especialmente Lucia di Lammermoor, una partitura "inspirada, altamente dramática, y notable por la unidad y el tinte poético y sentimental que en toda ella reina" ${ }^{43}$.

El advenimiento al terreno operístico de Giuseppe Verdi habría de significar el origen del declive de la música italiana tras varios siglos de hegemonía en el mapa europeo. Sin dejar Esperanza de reconocer su inventiva poderosa y el vigoroso instinto dramático que le animaba, las óperas del italiano, en general, excluyendo quizá Rigoletto, adolecían de escasez de ideas melódicas, carencia de expresión y sentimiento, endeble armonía e instrumentación pobre y harto vulgar. Con motivo de la reposición de algunos títulos de Verdi en el Real, el musicógrafo hace balance de su obra artística:

Por la escena del Teatro Real han pasado, en efecto, como por cámara obscura, y dejando la misma o parecida impresión que los figurones de aquélla, el tremebundo Hernani, con toda su trompetería de grueso calibre; la Traviata, con su moral acción y su música patológicosentimental; el Ballo in maschera, con todo lo bueno y malo que su partitura contiene; Aida, con sus pretensiones alemanesco-wagnerianas; y el Rigoletto, en fin, que, a ser justos, forzoso es decir indemniza espléndidamente de los sustos que las anteriores óperas producen ${ }^{44}$.

En la misma línea de crítica mordaz e incisiva, Esperanza establece una clasificación de la creación verdiana en tres etapas netamente diferenciadas. A un primer período de "ruidosa música" y monotonía general, así en la inspiración melódica como el vocabulario armónico y orquestal, sucederá una fase de transición e incertidumbre, presidido el lenguaje de Verdi por la huella de la gran ópera francesa -se citan aquí explícitamente Don Carlo, La forza del destino y Simon Boccanegra-, que desembocaría, a partir de Aida, en la abjuración de la fórmula operística italiana para rendirse el compositor a la corriente wagnerista ${ }^{45}$. Con todo, si todavía en Aida Esperanza aprecia ciertos destellos de originalidad melódica, riqueza de colorido armónico e interés dramático,

42 La Integridad de la Patria (23.01.1879) [ESPERANZA (1906), vol. I: 179-180].

43 IEA, XXV/1 (08.01.1881) [ESPERANZA (1906), vol. I: 300].

44 La Integridad de la Patria (23.01.1879) [ESPERANZA (1906), vol. I: 178]. I: 88-91]. 
no obstante el seguimiento acusado de las doctrinas wagnerianas, Otello representaba el vivo y desafortunado ejemplo de la escuela "pseudoimitadora" de Wagner. En este trabajo, dejándose arrastrar el músico por su adhesión al germanismo, "la declamación lírica ha sustituido al verdadero canto; el afán de aparecer original ha llevado al arte a un gongorismo conceptuoso; y a la sublime claridad de la verdadera belleza ha sustituido en ocasiones un caos capaz de causar hastío y desaliento aun al más ardiente sectario de la escuela pseudo-imitadora de Wagner" ${ }^{46}$.

Aún tuvo Esperanza tiempo para asomarse al realismo del movimiento verista que se gestó en Italia a lo largo de la última década de siglo. Saludó entusiasmado Cavalleria rusticana, de Mascagni, alabando la expresividad y belleza de sus temas melódicos, la hondura dramática y su carácter genuinamente italiano ${ }^{47}$, si bien acogerá con frialdad L'amico Fritz, donde agotada la musa de la inspiración, el compositor habría vuelto las espaldas a la receta italiana para alistarse en las filas del ejército pseudowagneriano ${ }^{48}$. No salió mejor parado Ruggiero Leoncavallo en I pagliacci, a cuyo magnífico libreto, "modelo de concisión, sobriedad y energía”, se contraponía una música de corte ecléctico -acusando principalmente la impronta de Mascagni- y falta de relieve melódico ${ }^{49}$. No alcanzará Esperanza a ver consagrado a Puccini como operista de fama internacional. Apenas pudo vivir la première madrileña de Edgar en 1892, que le causa una impresión negativa: argumento inverosímil e insustancial y música débil, de lenguaje ampuloso y marcada filiación a las tesis wagneristas. Con acertada visión premonitoria, intuye sin embargo en Puccini un talento poco común y excepcionales dotes dramáticas, augurándole un futuro cuajado de éxitos ${ }^{50}$.

\section{Alemania y Francia}

No fue, por supuesto, Wagner el único representante alemán digno de interés para Esperanza, aunque el tema wagneriano, circunscrito a la figura del propio compositor o al alcance y trascendencia de sus postulados reformistas, asume un evidente protagonismo en múltiples escri-

46 IEA, XXXVI/9 (08.03.1892) [ESPERANZA (1906), vol. III: 17-18].

47 IEA, XXXV/1 (08.01.1891) [ESPERANZA (1906), vol. III:

48 IEA, XXXIX/12 (30.03.1895) [ESPERANZA (1906), vol. III: 260-263]. La fecha no es 8 de febrero, como recoge el libro.

49 IEA, XXXVI,/47 (22.12.1892) [ESPERANZA (1906), vol. III: 133-134]. 80-83]. tos, ejemplificando a menudo la modernidad llevada a sus límites extremos. Otros nombres suscitaron la atención del madrileño fuera del área de influencia wagneriana, ya por pertenecer a generaciones precedentes, como Mozart o Beethoven, ya en razón de que cultivaban un lenguaje más conservador, cercano al Clasicismo, caso de Brahms. Mozart aparece a los ojos de Esperanza como "ingenio colosal", de cuya escritura subraya la íntima unión que consiguiera entre la gravedad y carácter profundo de la música germana y la seducción melódica de cuño italianizante: "Aprovechando todos los elementos que al arte habían aportado, no sólo sus predecesores, sino sus contemporáneos, supo amalgamarlos de modo feliz, y crear un estilo nuevo, verdadero, universal, superior a cuanto hasta entonces se conocía, y que en algunos géneros no ha sido sobrepujado" ${ }^{51}$. Con Don Giovanni, según Esperanza la página más sublime, hermosa y dramática del arte lírico, Mozart condujo la ópera a su cima:

Dramática en alto grado; asombrosa y profunda en la expresión de las pasiones y en la pintura de los caracteres [...]; llena de melodías tan bellas como originales [...]; rica, cual ninguna, en detalles de armonía y en sutiles delicadezas de contrapunto [...], así como en detalles de instrumentación ${ }^{52}$.

En opinión de Esperanza, el maestro de Salzburgo, junto con Haydn, Beethoven y Mendelssohn, conformaban el cuarteto de "genios inmortales" del género instrumental clásico, poseedor cada autor de un vocabulario específico, trasunto de su personalidad y vivencias, pero compartiendo simultáneamente determinados rasgos comunes: la perfección en la forma, el dominio de los recursos instrumentales, la claridad y belleza de las ideas melódicas y un estilo, en conjunto, noble, vital y vigoroso ${ }^{53}$. Ubicado en una posición secundaria respecto a los músicos anteriores, Schubert, señala Esperanza, derrocha ingenio e inspiración melódica a raudales, si bien el desmesurado desarrollo en ciertas secciones dañaba la unidad y coherencia formal de muchas obras ${ }^{54}$. El mismo defecto le atribuye a Schumann, a lo que venían a sumarse su inhabilidad en el manejo de la forma y el dudoso

51 IEA, XXXI/42 (15.11.1887) [ESPERANZA (1906), vol. II: 311].

52 IEA, XXXI/42 (15.11.1887) [ESPERANZA (1906), vol. II: 313-314].

53 Esperanza muestra, no obstante, ciertas reservas ante los últimos cuartetos y sonatas para piano de Beethoven, dada la dificultad de comprensión que entrañaban. Alude, así, a su falta de transparencia y claridad melódicas, y al desarrollo de ideas en extremo complicadas, oscuras y, por lo mismo, ininteligibles. 378-380]. 
gusto por la vaguedad de expresión, dando como resultado una producción de calidad dispar, sembrada de espléndidas páginas desbordantes de pasión y sentimiento, y otras, en menor número, de factura irregular, con estructuras formales de construcción deficiente y pasajes de ambigüedad tonal ${ }^{55}$.

Esperanza no albergaba ningún género de dudas: lidera en solitario y sin rival la escuela alemana moderna la emblemática individualidad artística de Johannes Brahms, a quien considera el compositor contemporáneo más notable de esta nación ${ }^{56}$. Seguidor de la estela de Beethoven, adoptándolo como modelo, las piezas de Brahms "muestran, más que una inspiración espontánea, un espíritu concentrado, una expresión indefinible de tristeza y ternura al mismo tiempo, gran riqueza de armonía, ritmos originales, una gran sonoridad y marcada afición a los motivos populares, sobre todo húngaros, y una maestría que pocos alcanzan en la manera de escribir y expresar sus pensamientos" ${ }^{57}$. El vanguardismo de los poemas sinfónicos Don Juan, Muerte y transfiguración y Las travesuras de Till Eulenspiegel, de Richard Strauss, debió de provocar un fuerte impacto emocional en Esperanza, a causa de su naturaleza programática y lo avanzado del léxico armónico y orquestal, que diferían absolutamente de sus criterios estéticos. Aun constatando el colorido de la paleta armónica y la destreza exhibida en la orquestación, el dictamen general no pudo ser más desfavorable:

Ni por su forma, ni por su ausencia de claridad, ni por las ideas que encierran, pueden gustarnos unas composiciones que, bien miradas, más pueden tenerse por los delirios de una razón enferma, que por la descripción fantástica de sucesos que, ni aun con ayuda de apuntador (que no es otra cosa el programa que les acompaña), pueden entenderse ${ }^{58}$.

Si un compositor personifica la concepción estética que preconizaba Esperanza, éste fue, con seguridad, Giacomo Meyerbeer, "el Beethoven del arte dramático" como él mismo lo bautizara, en cuyas partituras vertidas al molde de la gran ópera francesa corrían parejas la fuerza dramática, el encanto melódico, la riqueza y variedad de las combinaciones armónicas y un amplio conocimiento de la técnica orquestal ${ }^{59}$. Gracias a Meyerbeer, comentará el musicógrafo,

55 IEA, XXX/9 (08.03.1886) [ESPERANZA (1906), vol. II: 163-165]. La fecha no es 8 de mayo, como indica el libro. II: 523].

56 IEA, XXXIII/47 (22.12.1889) [ESPERANZA (1906), vol. 364-365].

57 IEA, XLI/22 (15.06.1897) [ESPERANZA (1906), vol. III:

58 IEA, XLII/20 (30.05.1898) [ESPERANZA (1906), vol. III: 382]. 59 IEA, XXXVI/11 (22.03.1892) [ESPERANZA (1906), vol. III: 73]. presenciamos el nacimiento del modelo ideal de ópera, donde drama y música se interrelacionan mutuamente, sin que prevalezca un elemento sobre otro. En tal sentido, Roberto el diablo habría inaugurado esta nueva era, que alcanza su culminación con Los hugonotes, a juicio de Esperanza la creación principal del berlinés, magistral fusión de las escuelas italiana, francesa y alemana y, en definitiva, una de las obras más completas y acabadas de la historia de la música:

[...] y considerando las bellezas de primer orden de que la partición de Los hugonotes está sembrada; al ver aquel admirable conjunto de pasión, de gracia, de poesía y de elegancia; al pensar en la revolución que en el arte hizo con ella Meyerbeer [...], implantando de un solo golpe su individualidad y creando el drama lírico-histórico ${ }^{60}$.

Coetáneo de Meyerbeer, Esperanza acusa a Héctor Berlioz de introducir las tendencias musicales más radicales que habían invadido Francia, transformando el arte sonoro, singularmente desde la Sinfonía fantástica, "en una ciencia abstracta, en que las sutilidades metafísicas reemplazan a las emociones del alma y a la inspiración poética, y el lenguaje sublime y misterioso del pensamiento se convierte en un realismo antiartístico y anacrónico" ${ }^{61}$. Ello unido a la omnipresente sombra del wagnerismo, con su anhelo de hacer tabla rasa del orden establecido, explicaría el lamentable estado de la música en el país vecino. Autores como Bizet, Gounod, Delibes, Thomas o Saint-Saëns, honrosas excepciones en el firmamento francés, se erigieron en depositarios de la tradición que fundaran Hérold, Boieldieu, Halévy y Auber durante la primera mitad de siglo. En el extremo opuesto, la obra de Jules Massenet reflejaba fielmente ese grado de degeneración a que había llegado la mayor parte de la música gala:

Massenet y los que siguen su rumbo tratan de suplir el genio y la inspiración con armonías extrañas y desusadas, con efectos rítmicos y de sonoridad, brutal a veces [...], formando el todo un conjunto en que lo rico y exuberante de lo accesorio no basta a encubrir el descarnado esqueleto que en sus entrañas se columbra, y hace pensar si a aquél no le sobraría razón cuando exclamaba, parodiando el título de una conocida obra de Shakespeare, si será cosa convenida gritar tan alto cuando, en suma, hay tan poco que decir ${ }^{62}$. 388-389].

60 IEA, XXVI/10 (15.03.1882) [ESPERANZA (1906), vol. I: 61 IEA, XXVIII/24 (30.06.1884) [ESPERANZA (1906), vol. II: $68]$. 62 IEA, XXVIII/24 (30.06.1884) [ESPERANZA (1906), vol. II: 70]. 


\section{Esperanza y Sola y la música española}

Avalado por su opinión autorizada como cronista musical de La Ilustración Española y Americana, Esperanza brindó el más decidido apoyo a cuantas iniciativas se fraguaron con vistas a divulgar el género instrumental culto y su popularización en la capital madrileña. Así podemos entender su intensa y continuada labor de seguimiento de las temporadas artísticas de la Sociedad de Cuartetos y la Sociedad de Conciertos durante el período comprendido entre 1879 y los últimos años de siglo. A la Sociedad de Cuartetos, bajo la batuta de Jesús de Monasterio, Esperanza otorgará el honor de difundir por vez primera en España la música de cámara, coadyuvando a la depuración del gusto musical del aficionado filarmónico. A su juicio, este conjunto había cimentado su éxito en la confluencia de dos factores: el excelente nivel interpretativo que acreditaba ${ }^{63}$ y la selección de un repertorio "clásico", compuesto de títulos de Haydn, Mozart, Beethoven y Mendelssohn, "no sin satisfacer también a los ávidos de novedades con producciones de otros maestros que, si no del valer e importancia que las indicadas, por su seriedad y relativo mérito han merecido figurar al lado de aquellos dioses del arte" ${ }^{64}$. No menos destacables son las reseñas destinadas a cubrir las sesiones de la Sociedad de Conciertos, donde Esperanza, aunque aspire a la ecuanimidad en sus apreciaciones, afronta el examen crítico desde los inalterables criterios estéticos que profesaba. Lo atestiguan sus reiteradas protestas a lo largo de la década de 1890 contra el espíritu estrecho y exclusivista de los programas de concierto, que tenía su expresión más elocuente en la acusada predilección por las composiciones contemporáneas:

[...] he de seguir lamentándome de la injustificada preterición que en nuestros conciertos viene haciéndose de las obras de Haydn, del divino Mozart y de Mendelssohn, que siempre se oyen en las sesiones musicales de los Conservatorios de París y de Bélgica, harto más importantes que las nuestras; en los conciertos más clásicos de Alemania, y, en fin, en todas partes donde, sin intransigencias que no es posible razonar, se rinde culto a los grandes genios del arte ${ }^{65}$.

El debate en torno a la creación de la ópera española adquiere una importancia capital en el conjunto de la pro-

63 Son incontables las referencias de Esperanza a la destreza de ejecución de esta agrupación, haciendo recaer los mayores elogios sobre su amigo y violinista Jesús de Monasterio. 521]

64 IEA, XXXIII/47 (22.12.1889) [ESPERANZA (1906), vol. II:

65 IEA, XLI/7 (22.02.1897) [ESPERANZA (1906), vol. III: 344]. ducción periodística de Esperanza, consagrándole numerosos comentarios y no escasas reflexiones. Varias son las causas que, a su entender, habían malogrado la consecución de este proyecto: la mediocridad de los libretos, el desinterés de los cantantes españoles, la desprotección por parte del gobierno y las empresas teatrales, a lo que venía a añadirse, como eterno e irresoluble problema, la inexistencia de un compositor de primer orden dispuesto a acometer una empresa de tal envergadura ${ }^{66}$. Desvinculándose de quienes defendían la zarzuela como pilar sobre el que sustentar la constitución del drama lírico nacional y de aquellos otros que, reprochando su naturaleza híbrida y adulterada, ansiaban descubrir nuevas referencias, Esperanza evita pronunciarse y afirma que "lo que se necesita para fundar la ópera española es músico que la cree y Gobierno que la proteja" ${ }^{67}$. A falta del apoyo oficial y no prodigándose en exceso las iniciativas de índole privada, el crítico acogerá de buen grado cualquier tentativa con el propósito de impulsar este pensamiento aun a sabiendas que, a la postre, un porcentaje mayoritario de esos títulos murieran en el olvido. Recorren, pues, los textos de Esperanza algunos de los autores españoles más señalados que probaron fortuna en la escena operística durante el último cuarto de siglo, desde Valentín Zubiaurre a Emilio Serrano, pasando por José Espí, Ruperto Chapí, Tomás Bretón o Felipe Pedrell. Dos nombres despuntan entre los demás en virtud de los triunfos, a menudo pasajeros, que cosecharon con un puñado de obras: Emilio Serrano y Tomás Bretón. De las tres óperas analizadas de Serrano, Mitrídates, Juana la Loca e Irene de Otranto, todas sin salvedad, indica Esperanza, eran deudoras de las corrientes más innovadoras europeas, principalmente Wagner, con la consiguiente exuberancia de armonías y modulaciones y la primacía de la orquesta frente al canto. Le recomienda, a este respecto, manifestar "menos fervor y entusiasmo hacia modelos de efímera fama, y vea de conseguir con sus partituras aquella unión de la verdad dramática, del sentimiento melódico y de la riqueza armónica de buena ley que tan a maravilla realizó Meyerbeer" ${ }^{6}$. Esa misma influencia nociva advertirá Esperanza en las bretonianas Los amantes de Teruel y Garín, páginas pobladas de vaguedades tonales y secciones de exagerado desarrollo. La actitud crítica hacia el maestro salmantino iba a cambiar las tornas a raíz del estreno, en 1895, de La Dolores, al decir de Esperanza su pieza más relevante, merced a la cual Bretón habría dado un paso crucial

66 IEA, XXV/42 (15.11.1881) [ESPERANZA (1906), vol. I: 343]. I: 65].

67 Revista Europea, 7 (12.04.1874) [ESPERANZA (1906), vol. 68 IEA, XXXIV/11 (22.03.1890) [ESPERANZA (1906), vol. II: 
en favor de la instauración de una ópera nacional. Recalcó, como características esenciales de la partitura, su aliento vigoroso, la intensidad dramática, el españolismo que respiraba el libreto, junto con el acierto de fundamentar la música en motivos de raigambre popular ${ }^{69}$.

Esperanza reconoce en la zarzuela la auténtica y genuina ópera cómica española. Tras su restauración hacia mediados de siglo, ésta había caído en el abandono, dejando el legado del género chico, donde "es moneda corriente que, salvas tan contadas como honrosísimas excepciones, lo insulso de la literatura corra parejas con lo insípido y deslavazado de la música" ${ }^{70}$. Defensor a ultranza de la zarzuela grande, Esperanza expresará su admiración por Arrieta, Marqués, Fernández Caballero y, fundamentalmente, Ruperto Chapí, de cuyo catálogo pondera La Bruja, Mujer y Reina y Curro Vargas, esta última su página más brillante. En ella, el villenense, recurriendo como base melódica a diversos cantos folclóricos, había logrado llevar a la práctica las teorías que, a propósito de la gestación de una ópera nacional, formularon Eximeno y, en fechas más recientes, Pedrell ${ }^{71}$. Haciendo profesión de españolismo, Esperanza no muestra reparos en equiparar a Chapí con los más celebrados autores europeos del momento:

[...] por su feliz inspiración y por su mucho saber, no es sólo un gran maestro del arte patrio, sino uno de los compositores de más valía en el mundo musical, y cuyas obras pueden y deben figurar, sin desmerecer un punto, antes al contrario, al lado de las de los compositores modernos que más renombre gozan y más lauros alcanzan en el extranjero ${ }^{72}$.

Completa el pensamiento de Esperanza un asunto recurrente en sus escritos, el estado de decadencia del arte musical religioso en España derivado, básicamente, de la entrada de elementos profanos procedentes del teatro lírico. En la iglesia, anota éste, extinguidas sus más arraigadas tradiciones musicales, habían sentado sus reales la ópera y la zarzuela, "triviales engendros de escuelas extraviadas o de una ignorancia en la cual, por lo que se ve, no es ciertamente

69 IEA, XXXIX/16 (30.04.1895) [ESPERANZA (1906), vol. III: 272 y $277-279]$. Sin salirse de sus cauces habituales, Esperanza señala, como único defecto, el predominio de la orquesta en determinados pasajes y, de resultas de ello, la profusión de detalles instrumentales, el lujo de sonoridades y el abuso de armonías extrañas. 20].

70 IEA, XXXV/4 (30.01.1891) [ESPERANZA (1906), vol. III: 396-397].

71 IEA, XLIII/1 (08.01.1899) [ESPERANZA (1906), vol. III:

72 IEA, XLIII/1 (08.01.1899) [ESPERANZA (1906), vol. III: 399-400]. la modestia la virtud que más resplandece" ${ }^{73}$. Según Esperanza, a la música sagrada concernía, como finalidad primordial, contribuir a la expresión del sentimiento religioso, elevando el fiel hacia Dios. Se infiere de ello que la música a capella, libre del ropaje instrumental, cumplía, en mayor medida que ninguna, este cometido. No por tal razón Esperanza desdeña otros estilos, antes bien admitirá en el recinto sagrado cualquier forma y procedimiento musicales si nacían inspirados por la fe e imbuidos de espíritu religioso ${ }^{74}$. Ante la corrupción de la música eclesiástica, Esperanza propone una serie de medidas al objeto de fijar de nuevo su carácter primigenio: la obligación de ejecutar en el templo música de estilo noble y severo, henchida de sentimiento religioso, que moviera a la devoción al cristiano; promover la composición de páginas musicales revestidas de las cualidades precedentes; y la intervención de las autoridades eclesiásticas para velar por el exacto cumplimiento de las disposiciones del Concilio de Trento ${ }^{75}$. Así las cosas, Esperanza puso especial empeño en dar cuenta de todas aquellas actuaciones encaminadas a fomentar la reforma del género musical sacro, como la celebración del Congreso Católico Nacional de 1889 o el establecimiento, en 1895, de la "Asociación Isidoriana para la reforma de la música religiosa" ${ }^{76}$. Atendiendo a la gran importancia que el movimiento reformista concedía a la recuperación del repertorio polifónico-vocal renacentista, Esperanza no ahorrará ocasión para reivindicar el puesto hegemónico de la escuela musical religiosa española del siglo XVI. La expresión, en cuanto rasgo inherente de la música hispana del Renacimiento, propició "que España apareciese adelantada a otras naciones, y sus maestros superaran a todos los de su tiempo, aun los de más nombradía" ${ }^{77}$. No en vano, autores como Cristóbal de Morales y, algo más tarde, Tomás Luis de Victoria, anticipándose a Palestrina, habían explotado conscientemente el elemento expresivo en sus obras, al realzar el significado del texto mediante la música, ya enfatizando las palabras, ya reforzando el sentido íntimo de las mismas ${ }^{78}$. Entre los compositores de música sagrada contemporáneos, Esperanza no oculta su pasión, rayana en

73 La España Católica (28.09.1874) [ESPERANZA (1906), vol. I: 82]. II: 54]. 75 La España Católica (28.09.1874) [ESPERANZA (1906), vol.
I: 86]. 76 El propio Esperanza figuraba entre los miembros fundadores
de esta sociedad. Vid. La música religiosa en España, año I, no I, enero
1896.
77 IEA, XXXIX/27 (22.07.1895) [ESPERANZA (1906), vol. III:
291]. 78 IEA, XXX/17 (08.05.1886) [ESPERANZA (1906), vol. II:
193].

74 IEA, XXVIII/17 (08.05.1884) [ESPERANZA (1906), vol. 193]. 
veneración, hacia su maestro Eslava, "una de las más grandes glorias nacionales en el presente siglo", a quien alude como digno sucesor de Guerrero y Morales, pero aventajándoles por cuanto consiguió armonizar la severidad y perfección de la forma y el interés melódico. De esta suerte, confería verdad, expresión y colorido a toda composición sin menoscabo del clasicismo de su diseño formal ${ }^{79}$. Al navarro, por otra parte, debían atribuírsele los primeros e incipientes logros en la tarea de restauración del género musical religioso a través de su colección "Lira Sacro-Hispana", que permitió exhumar joyas valiosas de música sagrada, asignando a España un sitial de honor, sin parangón, en el marco europeo. Con ello, concluye Esperanza, Eslava sentaba las bases de la línea de investigación que, posteriormente, guiaría los esfuerzos musicológicos de Barbieri y Pedrell ${ }^{80}$. Resulta, cuando menos, curioso que Esperanza, muy crítico con la intromisión de la ópera en el medio religioso, renuncie a condenar la huella italianizante que impregna el catálogo de Eslava. Así describe su lenguaje estilístico:

Originalidad, verdad, clasicismo, riqueza de armonía y modulación, sin caer en las exageraciones tan frecuentes hoy en gran parte de los compositores modernos, sobriedad en la orquesta, grande inteligencia en el manejo de las voces y un espíritu profundamente filosófico ${ }^{81}$.

\section{Conclusiones}

Alentábamos con este estudio visitar las distintas parcelas que configuran la actividad crítica de José María Esperanza y Sola en el transcurso de tres décadas de ejercicio periodístico. Hombre de vasta cultura y sólida formación humanística, la amplitud de los intereses de Esperanza trasciende la mera reseña o artículo, convirtiendo sus textos en reflexiones críticas acerca de asuntos de naturaleza musical, con frecuentes incursiones en los ámbitos histórico, artístico, literario o filosófico, que enriquecen sobremanera el discurso argumentativo. Más allá de su propia condición de comentarista musical, Esperanza se revela como fino y elegante escritor, dotado de una prosa depurada, donde conviven, guardando un equilibrio satisfactorio, ingredientes tan heterogéneos y, en apariencia, contrapuestos como la crónica

79 IEA, XL/15 (22.04.1896) [ESPERANZA (1906), vol. III: 313-314]. 314-315].

80 IEA, XL/15 (22.04.1896) [ESPERANZA (1906), vol. III: vol. I: 17]. estrictamente descriptiva y el juicio evaluativo personal, el despliegue de erudición y la narración ágil, amena y desenfadada, los latinajos y el chascarrillo.

A la luz de las consideraciones expuestas en estas páginas, fácil es discernir las diferencias que separan el ideario estético de los dos grandes críticos del Madrid finisecular, Esperanza y Peña y Goñi ${ }^{82}$. Si éste representó la avanzadilla, la actitud abierta y sin prejuicios a la Europa musical contemporánea, el musicógrafo madrileño se sitúa cómodamente instalado en el inmovilismo -léase Mozart, Rossini o Meyerbeer- y reacio a aceptar otras formas, técnicas y estilos, pese a esforzarse en demostrar, no pocas veces sin argumentos de peso, que aplaudía los últimos progresos del arte musical, siempre y cuando respetaran las normas de la tradición y el buen gusto. Sentados estos principios, la figura de Richard Wagner aflora permanentemente como materia central en las deliberaciones de Esperanza, alrededor del cual giran sus comentarios más jugosos. El compositor alemán, huelga decirlo, entrañaba para el crítico una seria amenaza al orden vigente, ya que sus ambiciones reformistas, al amparo de una supuesta modernidad, socavaban gravemente el edificio musical construido desde el siglo XVII. De ahí se sigue que Esperanza apruebe tan sólo sus piezas más afines al modelo operístico italiano, esto es, aquellas donde la melodía límpida, regular y expresiva gobernaba el discurso musical, sin dejarse "avasallar" por el tejido armónico y orquestal.

De no menor valor para el historiador, la obra de Esperanza constituye una fuente documental de primera mano a fin de ahondar en el conocimiento de la vida musical española. Su variedad temática, que abraza todos los géneros, desde la ópera y la zarzuela hasta la música de cámara y orquestal, sin desatender la vertiente religiosa, permite estudiar con detalle las vicisitudes del arte sonoro durante la Restauración, sus hechos y personajes más sobresalientes, sus problemas y anhelos, sus triunfos y fracasos. En un momento de trascendentales cambios en la historia de la música occidental, Esperanza se aferra con lealtad inquebrantable a la tradición, reticente a los desarrollos y avances musicales más modernos, mientras asistía impotente al fin de una era que originaría, en breve plazo de tiempo, la disolución de la armonía tonal y las formas al uso.

82 Muy interesante, por otra parte, se nos antoja un estudio comparativo entre Esperanza y el riojano Miguel Salvador Carreras, crítico de El Globo entre 1904 y 1913. Receptivo éste, sin embargo, a las novedades de Debussy, Strauss o el último Albéniz, la crítica de Salvador guarda ciertas similitudes con Esperanza por su función pedagógica, el talante moderado y tolerante, la ironía y el sentido del humor. $C f r$. CASCUDO (2012): 1-54. 


\section{Bibliografía}

B. Márquez, Miguel, "D. Abelardo de Carlos y "La Ilustración Española y Americana", Ámbitos, 13-14 (Sevilla, 2005): 185-209.

Borrell Vidal, José, Sesenta años de música (1876-1936). Impresiones y comentarios, Madrid, Editorial Dosat, 1945.

Carmena y Millán, Luis, Crónica de la ópera italiana en Madrid. Desde 1738 hasta nuestros días, Madrid, ICCMU (edición facsímil), 2004.

Casares Rodicio, Emilio, "La crítica musical en el XIX español. Panorama general", en Casares Rodicio, Emilio y Alonso González, Celsa (dirs.), La música española en el siglo XIX, Oviedo, Universidad de Oviedo, 1995: 463-491.

Casares Rodicio, Emilio, "José María Esperanza y Sola”, en Casares Rodicio, Emilio (dir. y coord.), Diccionario de la Música Española e Hispanoamericana, Madrid, Sociedad General de Autores y Editores, 1999, vol. 4: 768-769.

Cascudo, Teresa, "Humor y pedagogía en las crónicas de Miguel Salvador, el crítico buen aficionado de El Globo (1904-1913)", en Cascudo, Teresa y Palacios, María (eds.), Los Señores de la Crítica: Periodismo musical e ideología del modernismo en Madrid (1900-1950), Sevilla, Editorial Doble J, 2012: 1-54.

Esperanza y Sola, José María, El Cristianismo y el Derecho, Madrid, Aguado, 1858.

Esperanza y Sola, José María, Treinta años de crítica musical, Madrid, Establecimiento tipográfico de la viuda e hijos de Tello, 1906, 3 vols.

Gonzalo Delgado, Sonia, "El discurso crítico de José María Esperanza y Sola. Una primera aproximación”, en Marín López, Javier, Gan Quesada, Germán, Torres Clemente, Elena y Ramos López, Pilar (eds.), Musi- cología global, musicología local, Madrid, Sociedad Española de Musicología, 2013: 1677-1698.

Gracia Iberni, Luis, "La crítica periodística madrileña fin de siglo: Peña y Goñi”, en Barce, Ramón (coord.), Actualidad y futuro de la zarzuela. Actas de las jornadas celebradas en Madrid del 6 al 9 de noviembre de 1991, Madrid, Alpuerto, 1994: 201-213.

Gracia Iberni, Luis, "Cien años de Antonio Peña y Goñi”, Cuadernos de Música Iberoamericana, 4 (Madrid, 1997): 3-13.

Gracia Iberni, Luis, “Antonio Peña y Goñi”, en Casares Rodicio, Emilio (dir. y coord.), Diccionario de la Música Española e Hispanoamericana, Madrid, Sociedad General de Autores y Editores, 2001, vol. 8: 581-583.

Hurtado, Leopoldo, Apuntes sobre crítica musical, Buenos Aires, Grupo Editor Latinoamericano, 1988.

Moya Martínez, María del Valle de, "Aproximación a la crítica musical madrileña del último tercio del siglo XIX", Ensayos, 12 (Albacete, 1997): 163-171.

Pedrell, Felipe, Diccionario biográfico y bibliográfico de músicos y escritores de música españoles, portugueses e hispanoamericanos antiguos y modernos: acopio de datos y documentos para servir a la historia del arte musical en nuestra nación, Barcelona, Tipografía de Víctor Berdós y Feliu, 1897.

Suárez, Federico, Santiago Masarnau y Las Conferencias de San Vicente de Paúl, Madrid, Ediciones Rialp, 1994.

Suárez García, José Ignacio, La recepción de la obra wagneriana en el Madrid decimonónico, Tesis doctoral, Universidad de Oviedo, 2002.

Subirá Puig, José, La música en la Academia. Historia de una sección, Madrid, Real Academia de Bellas Artes de San Fernando, 1980.

Uriarte, Eustoquio de, Estética y crítica musical, Barcelona, Juan Gili, 1904.

Recibido: 17.12 .2012

Aceptado: 02.11.2015 